\section{$\$$ Research Square}

Preprints are preliminary reports that have not undergone peer review.

They should not be considered conclusive, used to inform clinical practice, or referenced by the media as validated information.

\title{
Discrimination between Softwood and Hardwood based on Hemicellulose Content obtained with Portable Nuclear Magnetic Resonance
}

\section{Valeria Stagno ( $\nabla$ valeria.stagno@uniroma1.it )}

Sapienza University of Rome: Universita degli Studi di Roma La Sapienza https://orcid.org/0000-00018327-6325

\section{Sara Ricci}

Sapienza University of Rome: Universita degli Studi di Roma La Sapienza

Sveva Longo

ISPC CNR Istituto di scienze del patrimonio culturale

\section{Elena Verticchio}

Sapienza University of Rome: Universita degli Studi di Roma La Sapienza

\section{Francesca Frasca}

Sapienza University of Rome: Universita degli Studi di Roma La Sapienza

\section{Anna Maria Siani}

Sapienza University of Rome: Universita degli Studi di Roma La Sapienza

\section{Silvia Capuani}

ISC CNR: Istituto dei Sistemi Complessi Consiglio Nazionale delle Ricerche

\section{Research Article}

Keywords: Portable NMR, softwood and hardwood, hemicellulose, bound water, NMR relaxation

Posted Date: March 2nd, 2022

DOI: https://doi.org/10.21203/rs.3.rs-1359070/v1

License: (c) (1) This work is licensed under a Creative Commons Attribution 4.0 International License. Read Full License 


\section{Abstract}

Wood is a hygroscopic material that can reach an equilibrium moisture content when ambient temperature and relative humidity are constant. Moisture affects all properties of wood, as well as its preservative treatment. The hygroscopic behavior of wood can be attributed to the hydroxyl groups of its constituents. Since hemicellulose shows the greatest water affinity, it can be considered the main responsible for water entering into the wood mass. Below the fiber saturation point (FSP), wood moisture is only stored in the cell walls. Proton Nuclear Magnetic Resonance (NMR) is a relative method used for the evaluation of moisture content distribution in wood and NMR relaxation is an excellent tool to study the hygroscopic behavior of different woods below the fiber saturation point. This work aimed to test the hypothesis of discriminating among softwoods and hardwoods of different botanical species and identifying further sub-clusters of woods on the basis of the NMR proton spin-spin $\left(T_{2}\right)$ and spin-lattice $\left(T_{1}\right)$ relaxation times of their cell wall water in the hygroscopic moisture range. Towards this goal, a portable low-field NMR instrument was used to develop a specific non-invasive NMR protocol for in situ investigation useful in the wood industry and/or cultural heritage applications.

\section{Introduction}

Wood is a biological heterogeneous and anisotropic porous material (Capuani et al. 2020). It is characterized by fibers with a cell wall composed of natural polymers, such as cellulose, hemicellulose, and lignin. Among them, cellulose can be considered the most abundant component of wood (Alesiani et al. 2005). Wood can be also described as a porous system with strongly variable and multi-scale porosity. In particular, each wooden species has pores, such as pits, perforations, and the lumen of vessels, tracheids, and fibers, with peculiar dimensions and spatial organization (Capuani et al. 2020; Stagno et al. 2021a).

Wood is classified as softwood and hardwood. Softwood has a quite homogeneous microstructure mostly dominated by one kind of structure, called tracheid (Capuani et al. 2020; Stagno et al. 2021a). Different from softwood, hardwood has more complex anatomical features and greater structural variation (Stagno et al. 2021a). Indeed, its microstructure is made up of conducting elements, i.e. vessels, and strength-giving elements, i.e. fibers.

Furthermore, due to its hygroscopicity, wood can absorb moisture from the surrounding environment in the form of vapor or liquid water. Moisture affects all properties of wood. While moisture in the cell lumens only produces an increment of weight (Tsoumis 1991), moisture contained in cell walls influences the mechanical and thermal properties of wood (Bartolucci et al. 2021). Moisture content (MC) of wood also affects its resistance to decay and insects as well as its preservative treatment (Tsoumis 1991). At constant temperature $(T)$ and relative humidity $(R H)$, wood reaches an equilibrium state characterized by a certain equilibrium moisture content (EMC) (Glass Samuel V; Zelinka 2010). A sorption isotherm is a discrete representation of equilibrium moisture states of wood with its surrounding environment and each state is attained after either adsorption or desorption of water molecules (Engelund et al. 2013). 
A central role in the hygroscopic behavior of wood can be ascribable to the hydroxyls of its constituents. Cellulose and hemicellulose have a higher content of hydroxyl groups than lignin. However, because cellulose is mostly in crystalline form that is not accessible to water, hemicellulose is considered to have a greater affinity to water (Schirarend 1986; Berry and Roderick 2005; Kulasinski et al. 2015). So, hydroxyl groups of hemicellulose catch water molecules by forming hydrogen bonds and are responsible for moisture entering the wood mass. Since softwoods and hardwoods show a different hemicellulose content, i.e. hardwoods have more hemicellulose than softwoods (Holtzapple 2003; García Esteban et al. 2005), distinct hygroscopic behavior of their cell walls is expected (Elder and Houtman 2013). When dried wood is taken at room temperature, at least a monomolecular layer of water is bonded to its constituents (Chami Khazraji and Robert 2013) and, its cell walls start swelling. Then, other water molecules align above those are associated with the hydroxyl groups and form H-bonds (Berry and Roderick 2005). The result is a water poly-molecular layer. An additional part may enter by capillarity condensation in the cell wall voids and pits but, it is considered insignificant below 99.5\% RH (Thygesen et al. 2010). The fiber saturation point (FSP) is the moisture content that occurs when cell walls are saturated with water and cell lumens are empty. At this point, cell walls stop swelling and, the strength of the timber no longer changes with the moisture content (Berry and Roderick 2005). Below the FSP, only bound water is present in wood, and water in the smaller pores of cell walls shows a switching behavior between liquid and vapor phases (Beckstein and Sansom 2003). Above the FSP, water starts filling cells lumens as free water. Conventionally, the FSP is set around $30 \%$ of wood moisture content. However, it can also be considered as the wood EMC when RH is close to 100\% (Berry and Roderick 2005).

The EMC is also affected by the wood sample history and, this phenomenon is known as sorption hysteresis. As an example, when a greenwood sample is dried, its EMC reached for adsorption will be lower than its EMC attained for desorption (Glass Samuel V; Zelinka 2010). Furthermore, it has been noticed that around $60-70 \% \mathrm{RH}$, the sorption isotherm of wood exhibits an upward bend. This behavior can be explainable by the softening of amorphous polymers (Olsson and Salmén 2004; Engelund et al. 2013). During softening, the viscosity and rigidity of the wood polymeric network are reduced because of the transition of its amorphous parts from a glassy state to a rubbery state (Engelund et al. 2013). Due to this process, the cell wall capacity of accommodating water molecules might increase. At room temperature, softening of hemicelluloses occurs around 75\% RH (Olsson and Salmén 2004; Engelund et al. 2013).

Nuclear Magnetic Resonance (NMR) is a relative method used for the evaluation of moisture content distribution in wood and masonry (Camuffo 2018). Compared to traditional relative methods for moisture content evaluation, the main advantages of NMR are the accuracy in moisture content determination and the greater penetration depth (European Committee for Standardization 2017). Portable Low-field Nuclear Magnetic Resonance (LFNMR) has been used to study different water compartments within the wood structure with particular interest for the over-hygroscopic range where water can be found not only in the cell wall but also in cell lumina and other voids with different sizes (Fredriksson and Thygesen 2017; Stagno et al. 2021c). These studies (Menon et al. 1987; Araujo et al. 1992; Labbé et al. 2002; Labbé et al. 2006; Almeida et al. 2007; Thygesen and Elder 2009; Elder and Houtman 2013; Fredriksson and Thygesen 
2017; Stagno et al. 2020; Stagno et al. 2021c) highlighted the LFNMR potential in characterizing water compartments of wood for probing its different anatomical elements. On the other hand, water in wood in the hygroscopic range (i.e. below the FSP) is only located in the cell wall compartment. However, cell wall water has also been separated into tightly bound to macromolecules and less bound to cell walls (Casieri et al. 2004; Fantazzini et al. 2006; Thygesen and Elder 2009; Bonnet et al. 2017; Rostom et al. 2020). All the aforementioned works pointed out that water is an excellent probe of wood characteristics because it is sensitive to wood ultrastructure. Moreover, water features in wood can be used to assess the wood morphology and hygroscopic behavior.

This work aimed to exploit the possibility to discriminate among different wood samples belonging to softwood and hardwood groups and identify possible sub-clusters of woods on the base of NMR relaxation of their cell wall water in the hygroscopic range. Towards this goal, a portable LFNMR instrument was used to develop a specific non-invasive NMR protocol for in situ investigation useful in the wood industry and/or cultural heritage applications.

\section{Experimental}

\subsection{Materials}

Fifteen cylinder-like wood samples (Table 1) of $2.5 \mathrm{~cm}$ in height and $3 \mathrm{~cm}$ in diameter were studied. The samples were previously dried inside the Universal Memmert Oven stove at a temperature $(T)$ of $103.5 \pm$ $0.5^{\circ} \mathrm{C}$ for 24 hours. Their botanical species and their common name are reported in Table 1. 
Table 1

Botanical species and common name of the samples, their densities, and wood group softwood (S) or hardwood (H).

\begin{tabular}{|llll|}
\hline Botanical species & Common name & Density $\left(\mathrm{kg} / \mathrm{m}^{3}\right)$ & Wood group \\
\hline Mitragyna ciliata & bahia walnut & $530 \pm 40$ & $\mathrm{H}$ \\
\hline Populus alba & white poplar & $480 \pm 40$ & $\mathrm{H}$ \\
\hline Picea abies & red spruce & $540 \pm 40$ & $\mathrm{~S}$ \\
\hline Abies alba & Russian silver fir & $530 \pm 40$ & $\mathrm{~S}$ \\
\hline Aningeria altissima & akatio walnut & $560 \pm 40$ & $\mathrm{H}$ \\
\hline Abies alba & European silver fir & $350 \pm 30$ & $\mathrm{~S}$ \\
\hline Quercus petraea & sessile oak & $630 \pm 50$ & $\mathrm{H}$ \\
\hline Juglans nigra & English walnut & $680 \pm 50$ & $\mathrm{H}$ \\
\hline Aningeria altissima & tanganyika walnut & $520 \pm 40$ & $\mathrm{H}$ \\
\hline Entandrophragma cylindricum & sapele mahogany & $550 \pm 40$ & $\mathrm{H}$ \\
\hline Toona ciliata & Australian red cedar & $520 \pm 40$ & $\mathrm{~S}$ \\
\hline Pinus ponderosa & European Virginia pine & $510 \pm 40$ & $\mathrm{~S}$ \\
\hline Lovoa trichilioides & African walnut & $550 \pm 40$ & $\mathrm{H}$ \\
\hline Picea rubens & American red spruce & $520 \pm 40$ & $\mathrm{~S}$ \\
\hline Pinus ponderosa & American Virginia pine & $530 \pm 40$ & $\mathrm{~S}$ \\
\hline
\end{tabular}

Since in this study NMR acquisitions were performed at different RH levels and NMR signal acquired by portable NMR Bruker instrument is particularly sensitive to little RH variations, a climate chamber was realized by using a Styrofoam box with inner volume $43 \times 36 \times 30\left(\mathrm{~h} \times \mathrm{I}\right.$ x w) $\mathrm{cm}^{3}$ (see Fig. 1). Styrofoam was chosen because of its insulating properties to prevent vapor exchanges with the external environment. Indeed, according to Nilsson et al. (Nilsson 2018), a climate chamber is recommended to maintain temperature stability because temperature fluctuation of $\pm 0.1^{\circ} \mathrm{C}$ may produce an $\mathrm{RH}$ change of $\pm 0.5 \%$. To keep the box temperature constant, the air conditioning system set at $T=20^{\circ} \mathrm{C}$ was turned on during all the experiments time. In this way all measurements were performed by inserting the wood samples inside the box at a selected value of relative humidity and constant temperature of $T=20 \pm 1^{\circ} \mathrm{C}$, which were monitored by using the TROTEC BC06 thermo-hygrometer (uncertainty of $\pm 1^{\circ} \mathrm{C}$ within the measurement range $0^{\circ}$ to $40^{\circ} \mathrm{C}$ for $\mathrm{T}$ and $\pm 3.5 \%$ within the measurement range $20^{\circ}$ to $80^{\circ} \mathrm{C}$ for $\mathrm{RH}$ ).

In a first phase, named A, four samples corresponding to Russian silver fir, European Virginia pine, akatio walnut, and white poplar (see Table 1) were equilibrated at three levels of relative humidity equal to $\mathrm{RH}_{\mathrm{A} 1}$ $=46.0 \pm 3.5 \%, \mathrm{RH}_{\mathrm{A} 2}=78.0 \pm 3.5 \%$ and $\mathrm{RH}_{\mathrm{A} 3}=94.0 \pm 3.5 \%$ while in a second phase, named $\mathrm{B}$, all the 
samples were equilibrated at $\mathrm{RH}_{\mathrm{B}}=94.0 \pm 3.5 \%$ (see Fig. 1). $\mathrm{RH}_{\mathrm{A} 1}$ was the environmental relative humidity of the laboratory. $\mathrm{RH}_{\mathrm{A} 2}$ was obtained by adding in the box a container with $130 \mathrm{ml}$ of liquid water.

$\mathrm{RH}_{\mathrm{A} 3}$ was reached by using a saturated saline solution of potassium sulfate $\left(\mathrm{K}_{2} \mathrm{SO}_{4}\right)$ (Nilsson 2018). It is important to notice that the EMC of wood at the three $\mathrm{RH}$ levels is expected to be approximately $9 \%, 15 \%$, and 24\%, respectively, according to the EMC calculation table (Noack 1989; W.T. Simpson 1998; Glass Samuel V; Zelinka 2010).

\subsection{Methods}

\subsubsection{Wood density}

Average dried weight values by gravimetric method (Noack 1989) were obtained for each wood species. Masses of all dried wood samples were measured with an analytical balance BP211D Sartorius and their volume was calculated. Then, the density of each sample was expressed in $\mathrm{kg} / \mathrm{m}^{3}$.

\subsubsection{NMR relaxometry}

The NMR relaxometry measurements were performed using a BRUKER minispec mq-ProFiler with a single-sided magnet that generates a static magnetic field of $0.35 \mathrm{~T}$. Therefore, ${ }^{1} \mathrm{H}$ resonance frequency was equal to $17 \mathrm{MHz}$. The single-sided NMR was equipped with an RF probe for performing experiments by collecting NMR signal from a sample volume defined from the sample surface to $2 \mathrm{~mm}$ inside the sample itself (Stagno et al. 2021b). Hard radiofrequency pulses of duration equal to $6 \mu$ s and a dead time acquisition of $2 \mu$ s were used. In both phases $A$ and $B$ the longitudinal relaxation time $\left(T_{1}\right)$ was acquired by using a Saturation Recovery (SR) sequence with minimum/maximum variable delay time $(t)=1 / 800$ $\mathrm{ms}$, with a repetition time $(T R)=0.02 \mathrm{~s}$, number of averaged scans, NSA $=1024$, increment factor 1.2 . For each sample, the SR experiment was repeated five times to test the reproducibility of the $T_{1}$ measurement and calculate the standard error (STE) associated with the $T_{1}$ mean values. On the base of the measured $T_{1}$, the TR was set for the transversal relaxation time $\left(T_{2}\right)$ measurement, performed using a Carr-PurcellMeiboom-Gill (CPMG) sequence. The CPMG was carried out by selecting a delays list from $0.042 \mathrm{~ms}$ to $21 \mathrm{~ms}$, with TR $=500 \mathrm{~ms}, 500$ echoes, NSA $=1024$, and echo time, $\mathrm{TE}=42 \mu \mathrm{s}$. This TE allowed eliminating the contribution of solid wood (i.e. the contribution from immobile protons of the wood polymers) (Casieri et al. 2004), which was estimated to be less than $30 \mu$ s (Araujo et al. 1992; Hartley et al. 1996), in the $T_{2}$ measurements. Also in this case the experiment was repeated five times for each wood sample to extrapolate STE of the T2 mean values.

\subsection{Data processing}

To obtain the $T_{1}$ values, a bi-exponential function:

$$
S(t)=M_{1} \times\left[1-\exp \left(-\frac{t}{T_{1,1}}\right)\right]+M_{2} \times\left[1-\exp \left(\frac{t}{T_{1,2}}\right)\right]
$$


was fitted to experimental data. In Eq. 1, $T_{1,1}$ and $T_{1,2}$ are the spin-lattice relaxation times belonging to two different water compartments associated with the magnetizations $M_{1}$ and $M_{2}$, respectively, $S(t)$ is the NMR signal.

Similarly, to quantify $T_{2}$ values, a bi-exponential function

$$
S(T E)=M_{1} \times \exp \left(-\frac{T E}{T_{2,1}}\right)+M_{2} \times \exp \left(-\frac{T E}{T_{2,2}}\right)+C
$$

2

was fitted to the CPMG signal (S(TE)). $T_{2,1}$ and $T_{2,2}$ are the spin-spin relaxation time components with $\mathrm{M}_{1}$ and $\mathrm{M}_{2}$ the associated magnetizations and $\mathrm{c}$ a constant to consider the noise floor.

All data were elaborated by using OriginPro 8.5 software. The goodness of each fit was evaluated by using the $R^{2}$ (i.e. the $\mathrm{R}^{2}$ corrected for the number of the regressors).

Each $T_{1}$ and $T_{2}$ component measured at 46,78 , and $94 \% \mathrm{RH}$ was plotted as a function of the relative humidity. Then, the k-means clustering algorithm of Matlab2021a (Statistics and Machine Learning Toolbox), which computes the sum of absolute differences i.e. each centroid is the component-wise median of the points in that cluster, was performed to verify the existence of at least two clusters of $T_{1}$ and $T_{2}$ at $\mathrm{RH}_{\mathrm{B}}=94 \%$ among the fifteen samples. Furthermore, correlation plots among wood samples density and all measured relaxation components were obtained.

\section{Results}

In Table 1 dry density of woods is reported. For the four chosen wood samples (Russian silver fir, European Virginia pine, akatio walnut, and white poplar), $T_{1}$ and $T_{2}$ components obtained by Eq. (1) and Eq. (2), respectively, are shown in Table 2. Each relaxation component was then plotted as a function of the relative humidity as displayed in Fig. 2 and Fig. 3. 
Table 2

$T_{1}$ and $T_{2}$ components and their standard errors (STE) calculated at $\mathrm{RH}_{\mathrm{A} 1}=46, \mathrm{RH}_{\mathrm{A} 2}=78$, $\mathrm{RH}_{\mathrm{A} 3}=94 \%$ by using Eq. (1) and Eq. (2).

\begin{tabular}{|lllll|}
\hline & $T_{1,1}$ & $T_{1,2}$ & $T_{2,1}$ & $T_{2,2}$ \\
\hline Russian silver fir & & $46 \% \mathrm{RH}_{\mathrm{A} 1}$ & & \\
\hline European Virginia pine & $1.13 \pm 0.09$ & $54.32 \pm 4.10$ & $0.152 \pm 0.002$ & $0.53 \pm 0.01$ \\
\hline Akatio walnut & $1.19 \pm 0.05$ & $59.02 \pm 2.23$ & $0.152 \pm 0.004$ & $0.57 \pm 0.02$ \\
\hline White poplar & $1.34 \pm 0.08$ & $66.99 \pm 2.09$ & $0.152 \pm 0.004$ & $0.550 \pm 0.004$ \\
\hline & & $78 \% \mathrm{RH}$ & & \\
\hline Russian silver fir & $0.84 \pm 0.05$ & $46.91 \pm 2.50$ & $0.17 \pm 0.01$ & $0.60 \pm 0.01$ \\
\hline European Virginia pine & $1.01 \pm 0.09$ & $36.65 \pm 1.80$ & $0.180 \pm 0.004$ & $0.60 \pm 0.01$ \\
\hline Akatio walnut & $1.62 \pm 0.06$ & $44.34 \pm 1.95$ & $0.178 \pm 0.004$ & $0.87 \pm 0.01$ \\
\hline White poplar & $1.89 \pm 0.04$ & $52.00 \pm 1.83$ & $0.178 \pm 0.004$ & $0.98 \pm 0.01$ \\
\hline & & $94 \% \mathrm{RH}_{\mathrm{A} 3}$ & & \\
\hline Russian silver fir & $1.44 \pm 0.05$ & $36.51 \pm 1.48$ & $0.178 \pm 0.004$ & $0.69 \pm 0.01$ \\
\hline European Virginia pine & $1.39 \pm 0.12$ & $28.24 \pm 1.97$ & $0.20 \pm 0.01$ & $0.70 \pm 0.01$ \\
\hline Akatio walnut & $1.67 \pm 0.04$ & $30.33 \pm 0.64$ & $0.248 \pm 0.004$ & $1.33 \pm 0.01$ \\
\hline White poplar & $2.05 \pm 0.11$ & $39.49 \pm 1.71$ & $0.192 \pm 0.004$ & $1.38 \pm 0.02$ \\
\hline
\end{tabular}

Table 3 shows the longitudinal relaxation times of all the fifteen samples obtained by the bi-exponential function of Eq. (1). In Table 4 the transversal relaxation times obtained by Eq. (2) are displayed. Figure 4 shows the correlation plots among density and relaxation times. The cluster plots that were obtained by correlating the $T_{1,1}$ vs. $T_{2,2}$ (Fig. $5 \mathrm{a}$ ) and $T_{1,2}$ vs. $T_{2,2}$ (Fig. $5 \mathrm{~b}$ ) and by supposing the existence of two clusters in the k-means algorithm is shown in Fig. 5. Moreover, in Fig. 6a similar cluster plot but with three hypothesized clusters is shown. 
Table 3

$T_{1}$ components calculated by Eq. (1) and their standard errors (STE) at $\mathrm{RH}_{\mathrm{B}}=94 \%$ for the fifteen samples.

\begin{tabular}{|lll|}
\hline Common name & $T_{1,1} \pm$ STE $(\mathrm{ms})$ & $T_{1,2} \pm$ STE (ms) \\
\hline bahia walnut & $1.39 \pm 0.08$ & $26.76 \pm 1.37$ \\
\hline white poplar & $2.05 \pm 0.11$ & $39.49 \pm 1.71$ \\
\hline red spruce & $1.26 \pm 0.12$ & $33.09 \pm 0.61$ \\
\hline Russian silver fir & $1.44 \pm 0.05$ & $36.51 \pm 1.48$ \\
\hline akatio walnut & $1.67 \pm 0.04$ & $30.33 \pm 0.64$ \\
\hline European silver fir & $1.19 \pm 0.03$ & $23.64 \pm 0.76$ \\
\hline sessile oak & $1.69 \pm 0.19$ & $67.66 \pm 0.59$ \\
\hline English walnut & $2.55 \pm 0.06$ & $84.58 \pm 1.70$ \\
\hline tanganyika walnut & $1.66 \pm 0.06$ & $39.44 \pm 1.13$ \\
\hline sapele mahogany & $1.50 \pm 0.4$ & $81.13 \pm 2.33$ \\
\hline Australian red cedar & $1.67 \pm 0.23$ & $59.85 \pm 1.48$ \\
\hline European Virginia pine & $1.39 \pm 0.12$ & $28.24 \pm 1.97$ \\
\hline African walnut & $1.92 \pm 0.08$ & $28.38 \pm 0.87$ \\
\hline American red spruce & $1.15 \pm 0.17$ & $33.76 \pm 0.58$ \\
\hline American Virginia pine & $1.04 \pm 0.03$ & $22.80 \pm 0.59$ \\
\hline
\end{tabular}


Table 4

$T_{2}$ components calculated by Eq. (2) and their standard errors

(STE) at $\mathrm{RH}_{\mathrm{B}}=94 \%$ for the fifteen samples.

\begin{tabular}{|lll|}
\hline Common name & $T_{2,1} \pm$ STE $(\mathrm{ms})$ & $T_{2,2} \pm$ STE (ms) \\
\hline bahia walnut & $0.214 \pm 0.004$ & $1.098 \pm 0.004$ \\
\hline white poplar & $0.192 \pm 0.004$ & $1.38 \pm 0.02$ \\
\hline red spruce & $0.19 \pm 0.01$ & $0.64 \pm 0.01$ \\
\hline Russian silver fir & $0.178 \pm 0.004$ & $0.69 \pm 0.01$ \\
\hline akatio walnut & $0.24 \pm 0.01$ & $1.33 \pm 0.01$ \\
\hline European silver fir & $0.196 \pm 0.004$ & $0.806 \pm 0.004$ \\
\hline sessile oak & $0.280 \pm 0.004$ & $0.952 \pm 0.004$ \\
\hline English walnut & $0.216 \pm 0.004$ & $1.25 \pm 0.01$ \\
\hline tanganyika walnut & $0.190 \pm 0.004$ & $1.096 \pm 0.004$ \\
\hline sapele mahogany & $0.238 \pm 0.002$ & $1.546 \pm 0.004$ \\
\hline Australian red cedar & $0.22 \pm 0.01$ & $0.90 \pm 0.02$ \\
\hline European Virginia pine & $0.20 \pm 0.01$ & $0.70 \pm 0.01$ \\
\hline African walnut & $0.25 \pm 0.01$ & $1.606 \pm 0.004$ \\
\hline American red spruce & $0.214 \pm 0.004$ & $0.72 \pm 0.01$ \\
\hline American Virginia pine & $0.192 \pm 0.004$ & $0.636 \pm 0.004$ \\
\hline
\end{tabular}

\section{Discussion}

This work aimed to discriminate among different wood samples on the base of the NMR relaxation of their cell wall water in the hygroscopic range. To develop a non-invasive NMR protocol for in situ investigation useful in the wood industry and/or cultural heritage applications, a portable NMR instrument was used. In the following, to better deal with and discuss the various observations and results obtained, the discussion section was divided into several paragraphs.

\subsection{NMR relaxation times components assignment and their dependence on $\mathrm{RH}$}

Different behavior of the two components of $T_{1}$ relaxation and the two components of $T_{2}$ relaxation is highlighted in Figs. 2 and 3. Considering the longitudinal relaxation time, some authors (Fantazzini et al. 2006; Bonnet et al. 2017; Rostom et al. 2020) pointed out the existence of two different components 
below the FSP. A fast $T_{1}$ component of a few ms or hundreds of $\mu \mathrm{s}$, which is due to water bound to the cell walls, and a slow $T_{1}$ of tens of $\mathrm{ms}$, which is associated with the protons of wood polymers. In this regard, the component $T_{1,1}$ displayed in Fig. $2 \mathrm{a}$, which is of the order of few ms, can be attributed to bound water in the cell walls while the second component $T_{1,2}$ (Fig. $2 \mathrm{~b}$ ), much greater and around tens of $\mathrm{ms}$, can be associated with relatively immobile water within the wood polymers.

Regarding the transversal relaxation time, previous works (Araujo et al. 1992; Hartley et al. 1992; Labbé et al. 2002; Thygesen and Elder 2009) identified a $T_{2}$ component around 0.2-3 ms increasing with $\mathrm{RH}$ as bound water. Therefore, we can associate the fast component $T_{2,1}$ (Fig. 3a) with water protons tightly bound to macromolecules and the slow component $T_{2,2}(\mathrm{Fig}$. $3 \mathrm{~b})$ with protons of cell wall-bound water (Casieri et al. 2004; Thygesen and Elder 2009). On the other hand, as the investigated wood samples were below the fiber saturation point, we did not detect the lumen water that is characterized by $T_{2}$ around tens of milliseconds (Labbé et al. 2002). Moreover, because we used a TE = $0.04 \mathrm{~ms}$ in the CPMG experiments, we did not measure the faster $T_{2}$ component belonging to solid wood (Casieri et al. 2004), estimated to be around $0.01 \mathrm{~ms}$ by Labbè et al. (Labbé et al. 2002).

4.1.2 Cell walls reservoir. In Fig. 2, an exponential dependence on the relative humidity of the $T_{1}$ associated with the cell walls $\left(T_{1,1}\right)$ is visible for all four wood samples. Particularly, this component (Fig. 2a), ranging from a minimum of $0.8 \mathrm{~ms}$ to a maximum of $2 \mathrm{~ms}$, shows a quite different behavior among softwoods and hardwoods. For the two hardwoods, white poplar and akatio walnut, the $T_{1,1}$ appears to increase with the $\mathrm{RH}$ increment. This is due to the growing hydration of the wood cell walls which determines a slower longitudinal relaxation time. In particular, the $T_{1,1}$ increment is higher when $\mathrm{RH}$ increases from $\mathrm{RH}_{\mathrm{A} 1}=46 \%$ to $\mathrm{RH}_{\mathrm{A} 2}=78 \%$ while it is lower from $\mathrm{RH}_{\mathrm{A} 2}=78 \%$ to $\mathrm{RH}_{\mathrm{A} 3}=94 \%$. In the two softwoods, Russian silver fir and European Virginia pine, the $T_{1,1}$ seems to be constant when RH changes from $\mathrm{RH}_{\mathrm{A} 1}=46 \%$ to $\mathrm{RH}_{\mathrm{A} 2}=78 \%$ and it starts to increase rapidly when $\mathrm{RH}$ grows from $\mathrm{RH}_{\mathrm{A} 2}=78 \%$ to $\mathrm{RH}_{\mathrm{A} 3}=94 \%$ reaching a lower maximum value compared to that of the hardwoods. This result can be explained by the fact that the hardwood samples catch more water molecules thanks to their higher hemicellulose content compared to the softwood samples. Also in the softwoods, the $T_{1,1}$ increment is associated with the growing hydration of the cell walls, but this seems to be gained drastically for $\mathrm{RH}$ > $78 \%$. This behavior may be a consequence of the hemicellulose softening that at room temperature ( $T=$ $20^{\circ} \mathrm{C}$ ) occurs around $\mathrm{RH}=75 \%$ (Olsson and Salmén 2004; Engelund et al. 2013).

The $T_{2,2}$ component of wood cell walls (Fig. $3 \mathrm{~b}$ ), grows from 0.53 to $1.38 \mathrm{~ms}$ describing progressive hydration of the wood cell walls mainly ascribable to hemicelluloses softening. Its growth is faster above $\mathrm{RH}_{\mathrm{A} 2}=78 \%$ due to the glass transition of hemicelluloses as described by Engelund et al. (Engelund et al. 2013). This $T_{2}$ component also shows a distinct behavior among softwoods and hardwoods reflecting their different hygroscopicity. On this subject, , hardwoods have cell walls made by a higher amount of hemicellulose (Holtzapple 2003) that is characterized by a lot of polar groups ( $\mathrm{OH}$ groups) able to retain water increasing wood hygroscopicity (García Esteban et al. 2005).

Page $11 / 19$ 
4.1.3 Polymers water reservoir. The $T_{1,2}$ component in Fig. $2 \mathrm{~b}$ shows an opposite behavior as a function of $\mathrm{RH}$ compared to that of the $T_{1,1}$ (Fig. 2a). Starting from a value of $50-60 \mathrm{~ms}$ at $\mathrm{RH}_{\mathrm{A} 1}=46 \%$, the $T_{1,2}$ decreases for both softwoods and hardwoods with the increase of $\mathrm{RH}$, reaching a minimum value around 30-40 ms. This is explainable considering that water tightly bound to polymers gains mobility with the $\mathrm{RH}$ increment. In the solid-like range, this increase of mobility is associated with a speeding up of the spin-lattice relaxation time due to the faster exchange of energy between spins and lattice (Brown and Koenig 1992).

In this regard, the $T_{2,1}$ component (Fig. 3a) spanning from 0.15 to $0.24 \mathrm{~ms}$, appears to slightly grow during the $\mathrm{RH}$ increment except for akatio walnut that shows a rapid increase (from 0.18 to $0.25 \mathrm{~ms}$ ) when $\mathrm{RH}$ changes from 78 to $94 \%$. This observation can indicate greater mobility of water protons in akatio walnut macromolecules and that it is approaching the FSP. In fact, as described in the literature (Jankowska and Kozakiewicz 2016), the FSP is negatively correlated with the wood density so denser woods have a lower FSP. The akatio walnut sample investigated in this paper has the highest density (around $560 \mathrm{~kg} / \mathrm{m}^{3}$, see Table 1) among the other three samples and for this reason, a low FSP is expected. In general, the $T_{2,1}$ component is quite similar for softwoods and hardwoods and describes the slow variation of mobility of the water protons tightly bound to the macromolecules.

\subsection{Relaxation times vs. density correlation}

As expected, the plot in Fig. 4 suggests that $T_{1}$ moderately correlates with the wood dry density $\left(\mathrm{kg} / \mathrm{m}^{3}\right)$, as previously shown by Stagno et al. [3]. The dependence of $T_{1,1}$ and $T_{1,2}$ on the dry density of woods indicates that $T_{1}$ is also affected by intrinsic features of the wood. Particularly, English walnut is characterized by the longest $T_{1}$ and the highest dry density associated with its compact structure due to a diffuse-porous ring with infrequent pores and frequent tyloses [37]. Conversely, European silver fir has the lowest density and the shortest $T_{1}$ because of its homogeneous structure constituted by more than $95 \%$ of open elements, i.e. tracheids [3, 38].

\subsection{Clustering}

4.3.1 Two clusters hypothesis. The main purpose of clustering by hypothesizing two clusters was to detect a possible different behavior among softwoods and hardwoods based on the measured relaxation times. The plot in Fig. 5 a shows how the different species of wood are distributed according to their $T_{1,1}$ and $T_{2,2}$ relaxation times. A clear differentiation of cell wall reservoir between softwoods and hardwoods is visible. Softwoods cluster centroid is [1.22, 0.69], which indicates that softwood samples are distributed around the median value of $T_{1,1}=1.22 \mathrm{~ms}$ and of $T_{2,2}=0.69 \mathrm{~ms}$. Indeed, while hardwoods seem to be spread among different values of $T_{1}$, softwoods occupy a quite narrow region of the plot that roughly ranges from 1 to $1.5 \mathrm{~ms}$. Moreover, the hardwoods cluster centroid is [1.67, 1.25]. Indeed, hardwoods show higher values of $T_{2,2}$ if compared to softwoods. Softwoods, indeed, have $T_{2,2}$ always shorter than $0.806 \pm 0.004 \mathrm{~ms}$, and hardwoods always longer than $0.90 \pm 0.02 \mathrm{~ms}$. Basically, at $\mathrm{RH}_{\mathrm{B}}=$ 
$94 \%$ the cell wall reservoir of softwoods is characterized by lower values of $T_{1}$ and $T_{2}$ than the cell wall reservoir of hardwoods.

In Fig. $5 \mathrm{~b}$, a similar result is shown but considering the $T_{1,2}$ and $T_{2,1}$ components. Two different clusters can be observed: cluster 1 with a centroid of $[74.39,0.23]$ and cluster 2 with a centroid of $[30.33,0.20]$. As for the plot in Fig. $5 \mathrm{a}$, the $T_{1,2}$ component of hardwoods is spread to different values. On contrary, softwoods show shorter $T_{1,2}$. The $T_{2,1}$ component is quite similar for all the woods. This result suggests that on the base of the polymers water reservoir it is not possible to distinguish among softwood and hardwood samples because of their quite similar $T_{1}$ and $T_{2}$ relaxation times. Anyway, two clusters were detected with cluster 1 which contains four hardwoods (sessile oak, sapele mahogany, English walnut, and Australian red cedar) characterized by long $T_{1,2}$ and $T_{2,1}$ likely indicating greater hydration of their polymers.

4.3.2 Three clusters hypothesis. To evaluate the existence of other possible clusters by using the $T_{1,1}$ and $T_{2,2}$ components, which are the relaxation times that provided a good differentiation among softwoods and hardwoods, a three clusters analysis was performed and shown in Fig. 6. This plot suggests two subclusters of the hardwoods cluster. The cluster called hardwoods 2 , with centroid [2.05, 1.38], contains the samples with longer $T_{1,1}$ (English walnut, white poplar, and African walnut), whereas the cluster called hardwoods 1 , with centroid $[1.66,1.10]$, the samples with shorter $T_{1,1}$ (sapele mahogany, akatio walnut, bahia walnut, sessile oak, tanganyika walnut, and Australian red cedar).

\subsection{Final discussion}

In Fig. 7a schematic representation of the hygroscopic behavior of the wood cell wall polymers exploited in this work to discriminate between softwood and hardwood is displayed. Specifically, in parallel with the increase of $\mathrm{RH}$, the hemicellulose hydrates more. The hydroxyl groups of the hemicellulose capture water molecules through hydrogen bonds that affect the NMR relaxation times of the cell wall reservoir $\left(T_{1,1}\right.$ and $T_{2,2}$ ), which allow discriminating between softwood and hardwood. Hardwoods have a higher hemicellulose content compared to softwoods, therefore their cell walls can reach greater hydration with more water molecules that are bound to the hemicellulose hydroxyls.

\section{Conclusions}

In this work, we tested the hypothesis of discriminating among softwoods and hardwoods of different botanical species based on their NMR relaxation times. To this end, a non-invasive protocol was tested on fifteen softwood and hardwood samples below the fiber saturation point by using a portable low-field NMR instrument. The results obtained in this paper suggest that, to discriminate between different softwoods and hardwoods by NMR relaxation times, it is necessary to perform the NMR measurements below the FSP but at relative humidity higher than $75 \%$ that corresponds to the humidity at which the hemicellulose softening occurs. Moreover, both the transversal and longitudinal relaxation times of the cell walls bound water $\left(T_{1,1}\right.$ and $\left.T_{2,2}\right)$ and polymers water reservoirs $\left(T_{1,2}\right.$ and $\left.T_{2,1}\right)$ have to be quantified. 
Specifically, the NMR relaxation times associated with the cell walls water reservoir allow to discriminate among hardwoods and softwoods and between two sub-clusters of hardwoods. Furthermore, according to results obtained below the FSP, small RH variations might affect the relaxation times. A controlled environment with constant relative humidity and temperature is therefore highly recommended to perform non-biased NMR relaxation time measurement. The NMR protocol presented in this study can be enhanced by studying a greater number of wood species and including further NMR parameters, such as the water diffusion coefficient (Stagno et al. 2021a; Stagno et al. 2021c), which may reflect the different hygroscopic behavior of softwood and hardwood connected to the different ultrastructural composition of their cell walls.

In conclusion, although limited to only 15 botanical species, the non-invasive NMR protocol performed by a portable instrument, allowed preliminary discrimination among species of softwood and hardwood, which could be useful for the wood industry and/or cultural heritage applications.

\section{Declarations}

\section{Competing Interests}

The authors have no relevant financial or non-financial interests to disclose.

\section{Funding}

The authors declare that no funds, grants, or other support were received during the preparation of this manuscript.

\section{Author Contributions}

All authors contributed to the study conception and design. Material preparation, data collection and analysis were performed by Valeria Stagno, Sara Ricci, and Silvia Capuani. The first draft of the manuscript was written by Valeria Stagno and all authors commented on previous versions of the manuscript. All authors read and approved the final manuscript.

\section{Acknowledgments}

The authors thank the national Italian agreement between CRUI-CARE and Springer Nature for funding the article processing charge (APC). Frasca F. acknowledges fellowship funding from MUR (Ministero dell’Università e della Ricerca) under PON “Ricerca e Innovazione” 2014-2020 (D.M. 1062/2021).

\section{References}

1. Alesiani M, Proietti F, Capuani S, Paci M, Fioravanti M, Maraviglia B (2005) 13C CPMAS NMR spectroscopic analysis applied to wood characterization. Appl Magn Reson. https://doi.org/10.1007/BF03167005 
2. Almeida G, Gagné S, Hernández RE (2007) A NMR study of water distribution in hardwoods at several equilibrium moisture contents. Wood Sci Technol. https://doi.org/10.1007/s00226-006-01163

3. Araujo CD, MacKay AL, Hailey JRT, Whittall KP, Le H (1992) Proton magnetic resonance techniques for characterization of water in wood: application to white spruce. Wood Sci Technol. https://doi.org/10.1007/BF00194466

4. Bartolucci B, Frasca F, Siani AM, Bertolin C (2021) Calibration of acoustic emission parameters in relation to the equilibrium moisture content variations in a Pinus sylvestris beam. Appl Sci. https://doi.org/10.3390/app11115236

5. Beckstein O, Sansom MSP (2003) Liquid-vapor oscillations of water in hydrophobic nanopores. Proc Natl Acad Sci U S A. https://doi.org/10.1073/pnas.1136844100

6. Berry SL, Roderick ML (2005) Plant-water relations and the fibre saturation point. New Phytol.

7. Bonnet M, Courtier-Murias D, Faure P, Rodts S, Care S (2017) NMR determination of sorption isotherms in earlywood and latewood of Douglas fir. Identification of bound water components related to their local environment. Holzforschung. https://doi.org/10.1515/hf-2016-0152

8. Brown RD, Koenig SH (1992) 1 /T1p and Low-Field 1 / T1 of Tissue Water Protons Arise from Magnetization Transfer to Macromolecular Solid-State Broadened Lines. Magn Reson Med. https://doi.org/10.1002/mrm.1910280115

9. Camuffo D (2018) Standardization activity in the evaluation of moisture content. J Cult Herit. https://doi.org/10.1016/j.culher.2018.03.021

10. Capuani S, Stagno V, Missori M, Sadori L, Longo S (2020) High-resolution multiparametric MRI of contemporary and waterlogged archaeological wood. Magn Reson Chem.

https://doi.org/10.1002/mrc.5034

11. Casieri C, Senni L, Romagnoli M, Santamaria U, De Luca F (2004) Determination of moisture fraction in wood by mobile NMR device. J Magn Reson. https://doi.org/10.1016/j.jmr.2004.09.014

12. Chami Khazraji A, Robert $S$ (2013) Self-assembly and intermolecular forces when cellulose and water interact using molecular modeling. J Nanomater. https://doi.org/10.1155/2013/745979

13. Elder T, Houtman C (2013) Time-domain NMR study of the drying of hemicellulose extracted aspen (Populus tremuloides Michx.). Holzforschung. https://doi.org/10.1515/hf-2012-0130

14. Engelund ET, Thygesen LG, Svensson S, Hill CAS (2013) A critical discussion of the physics of woodwater interactions. Wood Sci Technol. https://doi.org/10.1007/s00226-012-0514-7

15. European Committee for Standardization (2017) EUROPEAN STANDARD EN 16682: Conservation of cultural heritage - Methods of measurement of moisture content in materials constituting immovable cultural heritage

16. Fantazzini P, MacCotta A, Gombia M, Garavaglia C, Brown RJS, Brai M (2006) Solid-liquid nuclear magnetic resonance relaxation and signal amplitude relationships with ranking of seasoned softwoods and hardwoods. J Appl Phys. https://doi.org/10.1063/1.2354322 
17. Fredriksson M, Thygesen LG (2017) The states of water in Norway spruce (Picea abies (L.) Karst.) studied by low-field nuclear magnetic resonance (LFNMR) relaxometry: Assignment of free-water populations based on quantitative wood anatomy. Holzforschung. https://doi.org/10.1515/hf-20160044

18. García Esteban L, Gril J, De Palacios De Palacios P, Guindeo Casasús A (2005) Reduction of wood hygroscopicity and associated dimensional response by repeated humidity cycles. Ann For Sci. https://doi.org/10.1051/forest:2005020

19. Glass Samuel V; Zelinka SL (2010) Wood Handbook, Chapter 04: Moisture Relations and Physical Properties of Wood. Wood Handb wood as an Eng Mater

20. Hartley ID, Avramidis S, MacKay AL (1996) H-NMR studies of water interactions in sitka spruce and western hemlock: Moisture content determination and second moments. Wood Sci Technol. https://doi.org/10.1007/BF00224966

21. Hartley ID, Kamke FA, Peemoeller H (1992) Cluster theory for water sorption in wood. Wood Sci Technol. https://doi.org/10.1007/BF00194465

22. Holtzapple MT (2003) HEMICELLULOSES. In: Encyclopedia of Food Sciences and Nutrition

23. Jankowska A, Kozakiewicz P (2016) Determination of fibre saturation point of selected tropical wood species using different methods. Drewno. https://doi.org/10.12841/wood.1644-3985.C07.12

24. Kulasinski K, Guyer R, Derome D, Carmeliet J (2015) Water Adsorption in Wood MicrofibrilHemicellulose System: Role of the Crystalline-Amorphous Interface. Biomacromolecules. https://doi.org/10.1021/acs.biomac.5b00878

25. Labbé N, De Jéso B, Lartigue JC, Daudé G, Pétraud M, Ratier M (2006) Time-domain 1H NMR characterization of the liquid phase in greenwood. Holzforschung. https://doi.org/10.1515/HF.2006.043

26. Labbé N, De Jéso B, Lartigue JC, Daudé G, Pétraud M, Ratier M (2002) Moisture content and extractive materials in maritime pine wood by low field $1 \mathrm{H}$ NMR. Holzforschung. https://doi.org/10.1515/HF.2002.005

27. Menon RS, MaCkay AL, Hailey JRT, Bloom M, Burgess AE, Swanson JS (1987) An NMR determination of the physiological water distribution in wood during drying. J Appl Polym Sci. https://doi.org/10.1002/app.1987.070330408

28. Nilsson LO (2018) Methods of measuring moisture in building materials and structures: State-of-theart report of the rilem technical committee 248-mmb. In: RILEM State-of-the-Art Reports

29. Noack D (1989) Wood-Water Relations . Christen Skaar. Q Rev Biol. https://doi.org/10.1086/416506

30. Olsson AM, Salmén L (2004) The softening behavior of hemicelluloses related to moisture. In: ACS Symposium Series

31. Rostom L, Courtier-Murias D, Rodts S, Care S (2020) Investigation of the effect of aging on wood hygroscopicity by 2D 1H NMR relaxometry. Holzforschung. https://doi.org/10.1515/hf-2019-0052 
32. Schirarend C (1986) Siau, J. F., Transport Processes in Wood. Springer Series in Wood Science, IX + 254 S., 123 Figs., 20 Tab. Springer-Verlag. Berlin-Heidelberg, 1984. ISBN 3-540-12574-4. Preis: DM 89.-. Feddes Repert. https://doi.org/10.1002/fedr.4910970721

33. Stagno V, Egizi F, Corticelli F, Morandi V, Valle F, Costantini G, Longo S, Capuani S (2021a) Microstructural features assessment of different waterlogged wood species by NMR diffusion validated with complementary techniques. Magn Reson Imaging. https://doi.org/10.1016/j.mri.2021.08.010

34. Stagno V, Genova C, Zoratto N, Favero G, Capuani S (2021b) Single-Sided Portable NMR Investigation to Assess and Monitor Cleaning Action of PVA-Borax Hydrogel in Travertine and Lecce Stone. Molecules. https://doi.org/10.3390/molecules26123697

35. Stagno V, Longo S, Capuani S (2020) Effect of age on Pine wood microstructure studied by microMRI and diffusion-NMR. 2020 IMEKO TC-4 Int Conf Metrol Archaeol Cult Herit :570-574

36. Stagno V, Mailhiot S, Capuani S, Galotta G, Telkki VV (2021c) Testing 1D and 2D single-sided NMR on Roman age waterlogged woods. J Cult Herit. https://doi.org/10.1016/j.culher.2021.06.001

37. Thygesen LG, Elder T (2009) Moisture in untreated, acetylated, and furfurylated Norway spruce monitored during drying below fiber saturation using time domain NMR. Wood Fiber Sci

38. Thygesen LG, Tang Engelund E, Hoffmeyer P (2010) Water sorption in wood and modified wood at high values of relative humidity. Part I: Results for untreated, acetylated, and furfurylated Norway spruce. Holzforschung. https://doi.org/10.1515/HF.2010.044

39. Tsoumis G (1991) Science and technology of wood. Structure, properties, utilization. Sci Technol wood Struct Prop Util

40. W.T. Simpson (1998) Equilibrium moisture content of wood in outdoor locations in the united states and worldwide. For Prod Lab

\section{Figures}

\section{Figure 1}

Schematic representation of the climatic chamber composed by A) a sealed Styrofoam box with B) the TROTEC BC06 thermo-hygrometer used to monitor $\mathrm{RH}$ and T. In case 1) where $\mathrm{RH}_{\mathrm{A} 1}$ was $46 \%$ only the NMR mouse and the wood samples were placed inside the chamber, whereas in case 2) a container with $130 \mathrm{ml}$ of water was added to reach an $\mathrm{RH}_{\mathrm{A} 2}=78 \%$ and in case 3 ) a saturated saline solution of $\mathrm{K}_{2} \mathrm{SO}_{4}$ was used to reach $\mathrm{RH}_{\mathrm{A} 3 / \mathrm{B}}=94 \%$ 


\section{Figure 2}

(a) Plot of $T_{1,1}$ as a function of $\mathrm{RH}$ and (b) plot of $T_{1,2}$ as a function of $\mathrm{RH}$ for two softwoods (Russian silver fir and European Virginia pine) and for two hardwoods (white poplar and akatio walnut). Lines are for illustration purposes only

\section{Figure 3}

(a) Plot of $T_{2,1}$ as a function of $\mathrm{RH}$ and (b) plot of $T_{2,2}$ as a function of $\mathrm{RH}$ for two softwoods (Russian silver fir and European Virginia pine) and for two hardwoods (white poplar and akatio walnut). Lines are for illustration purposes only

\section{Figure 4}

Correlation plots among wood density and relaxation times components of the cell wall reservoir, (a) and (d), and of the polymers water reservoir, (b) and (c), at $\mathrm{RH}_{\mathrm{B}}=94 \%$. The displayed parameters $\mathrm{r}$ and $\mathrm{p}$ indicate the correlation coefficient and the p-value, respectively. The dashed red line indicates the significant linear correlation.

\section{Figure 5}

Cluster plots obtained by k-means algorithm between $T_{1,1}$ and $T_{2,2}(\mathrm{a})$ and $T_{1,2}$ and $T_{2,1}$ (b) of the fifteen samples at $\mathrm{RH}_{\mathrm{B}}=94 \%$. In (a) the centroid of cluster 1 is $[74.39,0.23]$ and of cluster 2 is $[30.33,0.20]$. In (b) softwoods cluster has centroid of $[1.22,0.69]$ and hardwoods cluster of $[1.67,1.25]$

\section{Figure 6}

Cluster plot obtained by hypothesizing three clusters in k-means algorithm between $T_{1,1}$ and $T_{2,2}$ of the fifteen samples at $\mathrm{RH}_{\mathrm{B}}=94 \%$. For the cluster of hardwoods 1 the centroid is $[1.66,1.10]$, for hardwoods 2 is $[2.05,1.38]$, whereas for softwoods is $[1.22,0.69]$ 
Schematic representation of cell wall polymers hydration in parallel with the $\mathrm{RH}$ increase. Hydroxyl groups of hemicellulose catch water molecules through hydrogen bonds. The $T_{1,1}$ and $T_{2,2}$ relaxation components measured in this work and associated with the cell wall-bound water can be considered as markers allowing to discriminate between softwood and hardwood on the base of their different hygroscopic behavior mainly due to their different hemicellulose amount. Hardwoods are characterized by a greater number of hemicellulose macromolecules that capture more water molecules during hydration. Therefore, on average, they show higher $T_{1,1}$ and $T_{2,2}$ than softwoods 